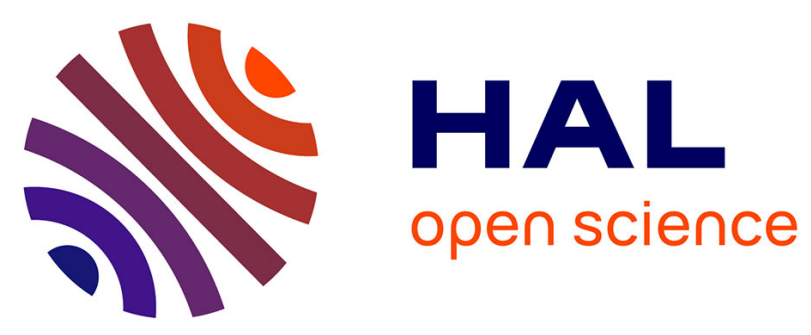

\title{
Worldwide invasion routes of the pinewood nematode: What can we infer from population genetics analyses?
}

Sophie Mallez, Chantal Castagnone, Margarida Espada, Paulo Vieira, Jonathan D. Eisenback, Mark Harrell, Manuel Mota, Takuya Aikawa, Mitsuteru Akiba, Hajime Kosaka, et al.

\section{To cite this version:}

Sophie Mallez, Chantal Castagnone, Margarida Espada, Paulo Vieira, Jonathan D. Eisenback, et al.. Worldwide invasion routes of the pinewood nematode: What can we infer from population genetics analyses?. Biological Invasions, 2015, 17 (4), pp.1199 - 1213. 10.1007/s10530-014-0788-9 . hal02638088

\section{HAL Id: hal-02638088 \\ https://hal.inrae.fr/hal-02638088}

Submitted on 15 Sep 2020

HAL is a multi-disciplinary open access archive for the deposit and dissemination of scientific research documents, whether they are published or not. The documents may come from teaching and research institutions in France or abroad, or from public or private research centers.
L'archive ouverte pluridisciplinaire HAL, est destinée au dépôt et à la diffusion de documents scientifiques de niveau recherche, publiés ou non, émanant des établissements d'enseignement et de recherche français ou étrangers, des laboratoires publics ou privés. 


\title{
Worldwide invasion routes of the pinewood nematode: What can we infer from population genetics analyses?
}

\author{
Sophie Mallez $\cdot$ Chantal Castagnone $\cdot$ Margarida Espada $\cdot$ Paulo Vieira \\ Jonathan D. Eisenback • Mark Harrell • Manuel Mota · Takuya Aikawa • \\ Mitsuteru Akiba $\cdot$ Hajime Kosaka $\cdot$ Philippe Castagnone-Sereno • \\ Thomas Guillemaud
}

\begin{abstract}
Identifying the invasion routes and determining the origin of new outbreaks of invasive species are of crucial importance if we are to understand the invasion process, improve or establish regulatory measures and, potentially, limit the damage. We focused here on the invasion of Europe by the pinewood nematode (PWN), Bursaphelenchus xylophilus (Steiner \& Buhrer, 1934; Nickle 1970; Nematoda: Aphelenchoididae), a major pest of forest ecosystems, native to North America and already invasive in Asia since the beginning of the twentieth century. We evaluated the genetic diversity and structure of worldwide field PWN samples by classical and Bayesian population genetics methods to
\end{abstract}

Electronic supplementary material The online version of this article (doi:10.1007/s10530 0140788 9) contains supple mentary material, which is available to authorized users.

S. Mallez $(\bowtie) \cdot C$. Castagnone · P. Castagnone Sereno ·

T. Guillemaud

UMR 1355 Institut Sophia Agrobiotech, INRA,

06903 Sophia Antipolis, France

e mail: mallez.sophie@gmail.com

S. Mallez - C. Castagnone - P. Castagnone Sereno .

T. Guillemaud

UMR Institut Sophia Agrobiotech, Université de Nice

Sophia Antipolis, 06903 Sophia Antipolis Cedex, France

S. Mallez - C. Castagnone - P. Castagnone Sereno ·

T. Guillemaud

UMR 7254 Institut Sophia Agrobiotech, CNRS,

06903 Sophia Antipolis Cedex, France determine the source of the European invasive populations and the number of introduction events in Europe. We found (1) a very strong spatial genetic structure in native PWN populations, (2) a very low level of polymorphism in each of the invaded areas and (3) contrasted results concerning the origin of European invasive populations. Our findings provide evidence for: (1) a large effect of genetic drift on the biological cycle of the PWN, due to intense demographic bottlenecks during tree infections, not compensated for by effective dispersal of its vector; (2) a single introduction event for each of the invaded areas in Japan and Europe and a small effective size for the introduced populations and (3) a mainland Portuguese origin for PWN populations from Madeira. However, more sophisticated methods of invasion route inference and broader sampling are required to conclusively determine the origin of the European outbreak.

\author{
M. Espada - P. Vieira - M. Mota \\ NemaLab/ICAAM Instituto de Ciências Agrárias e \\ Ambientais Mediterrânicas, Universidade de Évora, \\ Núcleo da Mitra, Ap. 94, 7002554 Évora, Portugal \\ J. D. Eisenback \\ Department of Plant Pathology, Physiology, and Weed \\ Science, Virginia Tech, Blacksburg, VA 24061, USA \\ M. Harrell \\ Nebraska Forest Service, University of Nebraska, Lincoln, \\ NE 68583 0815, USA
}


Keywords Bursaphelenchus xylophilus · Population genetics · Diversity · Genetic structure · Microsatellite markers $\cdot$ Pine wilt disease

\section{Introduction}

Several studies have shown that it is more effective to fight biological invasions in their initial stages than to try to eradicate the invader after its establishment, in terms of cost, time and management efficiency (Allendorf and Lundquist 2003; Simberloff et al. 2013). Deciphering geographic pathways followed by invasive species is a key first step in this direction. Many studies carried out over the last decade have tried to identify the invasion routes of several invasive species, including insects (Papura et al. 2012; Pascual et al. 2007; Perdereau et al. 2013; Zepeda-Paulo et al. 2010), plants (Kelager et al. 2013), nematodes (Boucher et al. 2013) and fungi (Fontaine et al. 2013). Indeed, this approach can be used to address various questions of both practical and theoretical concern (Estoup and Guillemaud 2010). Specifically, from a practical point of view, it may facilitate the design of strategies for preventing new invasions, by highlighting weaknesses in control and phytosanitary measures. It may help to improve the control or eradication of detrimental invasive species, through the identification of natural enemies in the native area, better understanding of the biology of populations and definition of the ecological features of invasive populations (Mack et al. 2000; Strong and Pemberton 2000; Tsutsui et al. 2000; van Wilgen et al. 2013). From a more fundamental point of view, the inference of invasion routes may provide useful information about the invasion process. The testing of ecological

T. Aikawa

Tohoku Research Center, Forestry and Forest Products Research Institute, Morioka, Iwate 020 0123, Japan

M. Akiba

Forest Pathology Laboratory, Forestry and Forest Products Research Institute, Matsunosato 1, Tsukuba, Ibaraki 305 8687, Japan

H. Kosaka

Kyushu Research Center, Forestry and Forest Products Research Institute, Kurokami 411 16,

Kumamoto 860 0862, Japan or evolutionary hypotheses explaining the success of biological invasions requires relevant comparisons between native and invasive populations (Facon et al. 2006; Keller and Taylor 2008; Puth and Post 2005; Wilson et al. 2009) and, thus, basic knowledge of the invasion routes used.

Here, we focused on the invasions of Europe by the pinewood nematode (PWN), Bursaphelenchus xylophilus (Steiner and Buhrer 1934; Nickle, 1970; Nematoda: Aphelenchoididae), a microscopic worm that reproduces sexually (Futai 2013). Outside North America (widely recognized as the native range of this species, Dropkin et al. 1981; Kiritani and Morimoto 2004; Wingfield et al. 1982), PWN is the causal agent of pine wilt disease (Mamiya 1972, 1976, 1983) and it poses a serious threat to pine forests worldwide, due to ecological and economic consequences of infestation (Mamiya 1988; Soliman et al. 2012; Suzuki 2002; Vicente et al. 2011). It was first observed outside its native range in Japan, in 1905, near Nagasaki (Mamiya 1988), where $28 \%$ of the 2.1 million ha of pine forest was found to be infested in 2000 (Mamiya 2004). It has since spread to other Asian countries, including China, Taiwan and South Korea (Moon et al. 2007). PWN was detected in the Setúbal Peninsula, close to Lisbon in Portugal, in 1999 (Mota et al. 1999) and new outbreaks have been identified since 2008 in the centre of mainland Portugal and on Madeira (Fonseca et al. 2012), as well as in Spain (Abelleira et al. 2011; Robertson et al. 2011). PWN was designated a quarantine organism by the European and Mediterranean Plant Protection Organization (OEPP/EPPO 1997) and the European Commission ruling (2006/133/CE) has imposed strict measures on the trade of wood, to limit the invasion. These measures have added significant costs to those already resulting from the destruction of pine forests.

Many studies have attempted to establish the origin of invasive outbreaks of PWN in different geographic areas (Cheng et al. 2008; Figueiredo et al. 2013; Fonseca et al. 2012; Metge and Burgermeister 2008; Pereira et al. 2013; Tares et al. 1992; Valadas et al. 2012a, b; Vieira et al. 2007; Zhang et al. 2008; Zhou et al. 2007). An Asian origin for European invasive populations of PWN was thus proposed (Figueiredo et al. 2013; Fonseca et al. 2012; Metge and Burgermeister 2008; Valadas et al. 2012b). However, these studies were subject to experimental limitations, such as the use of low-resolution markers (e.g. RAPD, 
RFLP), pools of individuals and/or collection samples. Thus, no study has as yet clearly investigated the worldwide invasion routes of PWN with relevant molecular markers, appropriate samples and the correct population genetics approaches as described by Estoup and Guillemaud (2010).

Therefore, the aim of this study was to perform population genetics analyses on natural PWN populations from around the world, with microsatellite markers developed previously (Mallez et al. 2013). In particular, we aimed to confirm the existence of the strong genetic structure in the native area of this species suggested by Mallez et al. (2013), through the use of a larger number of samples from different US states and hierarchical sampling. We also evaluated the genetic diversity of PWN populations from invaded areas, to obtain information about the number of introduction events. Finally, we investigated the relationships between populations in native and invaded areas, to clarify the invasion routes used by PWN. In particular, we investigated whether the European invasion resulted from an introduction independent of the Asian introduction or from successive introductions via Asia. We also analysed the relationships between invasive populations from mainland Portugal and Madeira.

\section{Materials and methods}

The biological system of the PWN and its generation time

The biological cycle of the PWN in natura is complex and involves at least two partners: the pine tree and the insect vector (Evans et al. 1996; Futai 2013 for a review). The PWN and its vector are closely associated and their life cycles closely match (Mamiya 1972). Thus, the PWN reproduce exclusively during summer once it invaded a susceptible pine tree (from June to September for the largest period). Its generation time is not precisely known in natura due to impossible direct observations of the PWN into the tree. However, from laboratory experiments, it was determined that the life cycle of the PWN depends mainly on the temperature, which determines its duration (Mamiya 1975). The generation time of the PWN may thus be very short and lasts from 45 days at $25{ }^{\circ} \mathrm{C}$ to about 12 days at $15{ }^{\circ} \mathrm{C}$, with temperature thresholds for development of $9.5^{\circ} \mathrm{C}$ for the minimum and $33{ }^{\circ} \mathrm{C}$ for the maximum (Mamiya 1975). Consequently, by coupling this information, the generation time of the PWN was approximated to 30 generations per year (by averaging the summer temperature to $25{ }^{\circ} \mathrm{C}$ and by considering the June September period for PWN reproduction). This is about 450 generations since the PWN introduction in Portugal and more than 3,200 generations since its introduction in Japan.

\section{Sampling}

Nematode samples were obtained from three different geographic areas: a part of the native area, the USA and two invaded areas, Japan and Portugal/Madeira. Thirty-four locations were sampled and 770 individuals were analysed in total: 18 locations from the USA (391 individuals), nine from mainland Portugal and Madeira (169 individuals) and seven from Japan (210 individuals). The PWN samples are listed and described in Table 1 and the locations from which the samples were collected are shown in Fig. 1. All individuals were extracted from wood samples collected directly from field locations. Each location sample originated from a single tree and consisted of seven to 36 individuals, at various stages. Nematodes were extracted with a sieve or a Baermann funnel (Viglierchio and Schmitt 1983). No permission was required to collect samples of PWN from the infested areas and we obtained an official agreement from the French authorities (\#2012060-0004) for the importation and manipulation of this quarantine organism at Institut Sophia Agrobiotech facilities. For some samples, extraction of individuals were carried out by our collaborators, who then sent them in DESS (Yoder et al. 2006). These samples were washed in distilled water before DNA extraction. For the other samples, DNA was extracted directly after the extraction of individuals from wood samples.

DNA extraction and genotyping of microsatellite loci

Single individuals were subjected to a thermal shock, as explained below, for DNA extraction (Castagnone et al. 2005). Each individual was hand-picked, transferred to $18 \mu \mathrm{l}$ of lysis buffer $\left(10 \times\right.$ Taq buffer with $\mathrm{MgCl}_{2}$, Taq Core Kits10, MP Biomedicals; $60 \mathrm{mg} \mathrm{ml}^{-1}$ proteinase $\mathrm{K}$ and sterile distilled $\mathrm{H}_{2} \mathrm{O}$ ) and placed at $-80{ }^{\circ} \mathrm{C}$ for 
Table 1 Characteristics and population genetics summary statistics of each sample of B. xylophilus used in this study

\begin{tabular}{|c|c|c|c|c|c|c|c|}
\hline Sample code & No. of individuals & Origin & Mean $\mathrm{Na}$ & $\mathrm{Max} \mathrm{Na}$ & $\mathrm{He}$ & Ho & Fis \\
\hline MO1 & 31 & USA Missouri Columbia & 3.25 & 8 & 0.33 & 0.27 & $0.19^{\mathrm{a}}$ \\
\hline MO2 & 23 & USA Missouri Columbia & 3.38 & 7 & 0.36 & 0.26 & $0.27^{\mathrm{a}}$ \\
\hline NE1 & 16 & USA Nebraska Davey & 2.00 & 4 & 0.20 & 0.18 & 0.09 \\
\hline NE2 & 15 & USA Nebraska Davey & 1.81 & 4 & 0.21 & 0.16 & 0.24 \\
\hline NE5 & 14 & USA Nebraska Pawnee Lake & 1.94 & 5 & 0.21 & 0.18 & 0.14 \\
\hline NE6 & 21 & USA Nebraska Pawnee Lake & 1.38 & 2 & 0.18 & 0.10 & $0.48^{\mathrm{a}}$ \\
\hline NE9 & 29 & USA Nebraska Pawnee Lake & 2.63 & 5 & 0.31 & 0.23 & $0.26^{\mathrm{a}}$ \\
\hline NE10 & 26 & USA Nebraska Pawnee Lake & 1.75 & 4 & 0.19 & 0.15 & $0.19^{\mathrm{a}}$ \\
\hline NE12 & 28 & USA Nebraska Conestoga Lake & 1.50 & 3 & 0.15 & 0.10 & $0.34^{\mathrm{a}}$ \\
\hline NE13b & 19 & USA Nebraska Pioneers Park & 2.38 & 5 & 0.28 & 0.20 & $0.31^{\mathrm{a}}$ \\
\hline NE14 & 28 & USA Nebraska Pioneers Park & 1.69 & 3 & 0.24 & 0.16 & $0.34^{\mathrm{a}}$ \\
\hline NE15 & 23 & USA Nebraska Pioneers Park & 2.25 & 5 & 0.22 & 0.14 & $0.38^{\mathrm{a}}$ \\
\hline NE19 & 16 & USA Nebraska UNL East Campus & 1.81 & 3 & 0.23 & 0.20 & 0.15 \\
\hline NE22 & 17 & USA Nebraska Lincoln & 2.00 & 5 & 0.28 & 0.20 & $0.28^{\mathrm{a}}$ \\
\hline NE23 & 25 & USA Nebraska Lincoln & 1.25 & 2 & 0.07 & 0.07 & 0.09 \\
\hline NE24 & 19 & USA Nebraska Lincoln & 1.31 & 2 & 0.07 & 0.06 & 0.15 \\
\hline VI9 & 22 & USA Virginia Midlothian & 1.50 & 3 & 0.16 & 0.14 & 0.14 \\
\hline MA1 & 19 & USA Massachusetts Worchester & 1.50 & 2 & 0.14 & 0.14 & 0.00 \\
\hline Jap120 & 23 & Japan Iwate Shiwa & 1 & 1 & & & \\
\hline Jap212 & 27 & Japan Iwate Shiwa & 1 & 1 & & & \\
\hline Jap308 & 25 & Japan Iwate Shiwa & 1 & 1 & & & \\
\hline Kasumig2 & 36 & Japan Ibaraki Kasumigaura & 1 & 1 & & & \\
\hline Kasumig3 & 29 & Japan Ibaraki Kasumigaura & 1.19 & 2 & 0.06 & 0.06 & 0.02 \\
\hline Kasumig5 & 35 & Japan Ibaraki Kasumigaura & 1 & 1 & & & \\
\hline Kosa & 35 & Japan Kumamoto Kosa & 1.25 & 2 & 0.06 & 0.05 & 0.03 \\
\hline Mad23PC & 12 & Madeira Island Porto da Cruz & 1 & 1 & & & \\
\hline $\operatorname{Mad} 24 \mathrm{C}$ & 7 & Madeira Island Calheta & 1 & 1 & & & \\
\hline $128 \mathrm{~S}$ & 17 & Portugal Setubal Grândola & 1.06 & 2 & 0.03 & 0.01 & $0.62^{\mathrm{a}}$ \\
\hline TR1 & 30 & Portugal Setubal Troia & 1 & 1 & & & \\
\hline TR2 & 27 & Portugal Setubal Troia & 1 & 1 & & & \\
\hline AM2 & 21 & Portugal Setubal Aguas de Moura & 1 & 1 & & & \\
\hline Comporta & 28 & Portugal Setubal Comporta & 1 & 1 & & & \\
\hline E182 & 13 & Portugal Coimbra Penela & 1 & 1 & & & \\
\hline E1069 & 14 & Portugal Viseu Castro Daire & 1 & 1 & & & \\
\hline
\end{tabular}

Mean $\mathrm{Na}$ is the mean number of alleles per sample over all loci, Max $\mathrm{Na}$ is the maximum number of alleles per locus in each sample, $\mathrm{He}$ is the expected heterozygosity and Ho is the observed heterozygosity. FIS was calculated as described by Weir and Cockerham (1984)

“" indicates that $\mathrm{Ho}, \mathrm{He}$ and FIS were not calculated, for samples with only monomorphic markers

${ }^{a}$ indicates that the result of the HWE test was significant at the $5 \%$ level after FDR correction (Benjamini and Hochberg 1995)

$60 \mathrm{~min}$. It was then immediately transferred to $60{ }^{\circ} \mathrm{C}$ for 60 min and, finally, to $95{ }^{\circ} \mathrm{C}$ for $15 \mathrm{~min}$ in a Biometra ${ }^{\circledR}$ T3-Thermoblock Thermocycler. We amplified 16 microsatellite loci in three multiplex PCRs: MA28 (5 microsatellite loci), MB28 (5 microsatellite loci) and MC33 (6 microsatellite loci), as described by Mallez et al. (2013). We excluded Bx07 from the MB28 multiplex reaction, because this marker is identical to 


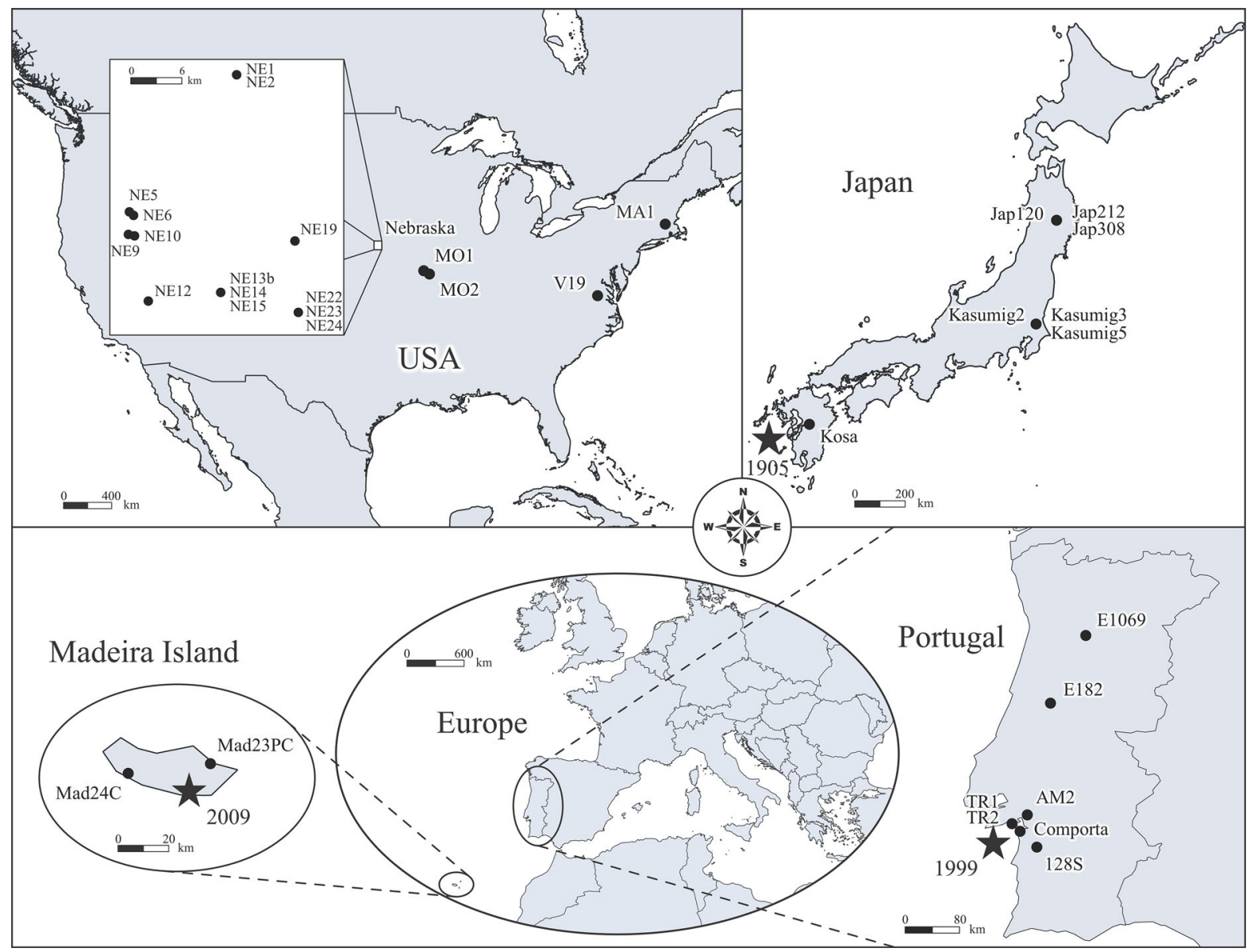

Fig. 1 Location of the sampling sites for B. xylophilus used in this study. Three different geographic areas are represented: the USA, a part of the native area, focusing on the Nebraska, and two different invaded areas, mainland Portugal and Madeira and

PWN 51 (Mallez et al. 2013). PCR amplifications were performed in $10 \mu \mathrm{l}$ containing $1 \times$ QIAGEN Multiplex Master Mix, $2 \mu \mathrm{M}$ of each primer, with forward primers labelled with a fluorescent dye (6-FAM, VIC, PET or NED) at the $5^{\prime}$ end, and $2 \mu \mathrm{l}$ of genomic DNA extracted by thermal shock. The amplification reactions were performed in a Biometra ${ }^{\circledR}$ T3-Thermoblock Thermocycler and included a 15 min denaturation step at $95{ }^{\circ} \mathrm{C}$, followed by 28 or 33 cycles (depending on the multiplex PCR) of $30 \mathrm{~s}$ at $94{ }^{\circ} \mathrm{C}, 1.5 \mathrm{~min}$ at $55^{\circ} \mathrm{C}$, and $1 \mathrm{~min}$ at $72{ }^{\circ} \mathrm{C}$, followed by a final extension step of $30 \mathrm{~min}$ at $60{ }^{\circ} \mathrm{C}$. Genotypes were determined with an ABI 3700 sequencer (Applied Biosystems), with the $500 \mathrm{LIZ}^{\mathrm{TM}}$ GeneScan ${ }^{\mathrm{TM}}$ size standard (Applied Biosystems) and Genemarker $^{\mathrm{TM}}$ version 1.75 software (SoftGenetics LLC).
Japan. The stars indicate the hypothetical entry points of PWN. The dates of first observation for each invaded area are indicated. The codes on the maps are the sample names. For more details, see Table 1

Data analyses

\section{Standard genetic analyses}

For each sample, we determined the maximum number of alleles detected over all loci (Max. Na), the mean number of alleles (Mean $\mathrm{Na}$ ) and the observed (Ho) and expected (He) heterozygosities per sample, with GENETIX version 4.05 (Belkhir et al. 1996 2004). We evaluated deviation from Hardy Weinberg equilibrium (HWE) with GENEPOP version 4.1.3 (Rousset 2008) and we quantified inferred deviations from HWE by calculating the Weir and Cockerham estimate of FIS (Weir and Cockerham 1984) with FSTAT version 2.9.3.2 (Goudet 2002). Linkage equilibrium between loci was assessed with 
the log likelihood ratio test, in GENEPOP (Rousset 2008). We took multiple testing (HWE tests) and the non-independence of tests (linkage tests) into account by performing false discovery rate (FDR) correction (Benjamini and Hochberg 1995) and sequential Bonferroni adjustment (Sokal and Rohlf 1995), respectively. Null allele frequencies were estimated with FREENA (Chapuis and Estoup 2007).

\section{Genetic structure analyses within areas}

All the analyses described in this section were performed within each area, for precise characterization of the nematode samples from the native area and the two invaded areas. We first tested the hypothesis of uniform genotype frequencies between samples, by Fisher's exact test (Raymond and Rousset 1995) implemented in GENEPOP (Rousset 2008). As nonindependent multiple tests were performed, sequential Bonferroni correction (Sokal and Rohlf 1995) was carried out to adjust significance levels. We also calculated Weir and Cockerham estimates of $F_{S T}$ (Weir and Cockerham 1984) between samples, corrected for null alleles with FREENA (Chapuis and Estoup 2007). We then studied the structure of the populations from each area by a Bayesian clustering approach, as implemented in STRUCTURE version 2.3 (Pritchard et al. 2000). An admixture model with correlated allele frequencies was used (Falush et al. 2003). The numbers of clusters tested, $K$, varied from 1 to 18 for the USA, from 1 to 7 for Japan and from 1 to 4 for Portugal/ Madeira. We carried out 20 independent runs for each value of $K$. Each run involved a Markov Chain Monte Carlo (MCMC) procedure with $10^{6}$ iterations, following a burn-in period of $2 \times 10^{5}$ iterations. Default values were maintained for all the other parameters. The number of clusters was determined both as described by Evanno et al. (2005) and automated in STRUCTURE HARVESTER (http://taylorO.biology. ucla.edu/struct harvest/index.php, Earl and vonHoldt 2012) and by checking all the bar plots of co-ancestry parameters for successive values of $K$. Using CLUMPP (Jakobsson and Rosenberg 2007), we identified the most frequent clustering patterns for each value of $K$ among the 20 runs, which we plotted with DISTRUCT version 1.1 (Rosenberg 2004). We checked the adequacy of the clustering patterns chosen for successive values of $K$.
In the USA, the hierarchical sampling in Nebraska allowed us to investigate the possible occurrence of isolation by distance (IBD). This involved assessment of the correlation between genetic distance (FST/ $(1-F S T))$ and the logarithm of geographic distance, for pairs of populations (Rousset 1997). We used the Mantel test in GENEPOP (Rousset 2008) and 20,000 permutations to assess the significance of the correlation.

\section{Relationships between the different areas}

We focused on the origin of the Portuguese mainland and island (Madeira) samples. The most probable source population, in North America or in Asia, for each Portuguese sample was investigated in several ways. More precisely, the aim of this part was to select the most probable scenario among the following scenarios: (1) a scenario with two independent introductions, in Asia and in Europe, from North America and (2) a scenario with two successive introductions, from North America to Asia and then from Asia to Europe.

We first analysed the FST values corrected for null alleles (Chapuis and Estoup 2007; Weir and Cockerham 1984) between each Portuguese sample and each American or Japanese sample. We then carried out an individual assignment likelihood analysis (Paetkau et al. 2004; Rannala and Mountain 1997), as in previous studies on invasion routes (Ciosi et al. 2008; Pascual et al. 2007) with GENECLASS2 software version 2.0 (Piry et al. 2004). This analysis involves calculating the mean individual assignment likelihood (denoted $\mathrm{L}_{i \rightarrow s}$ ) of each Portuguese sample $i$, to each possible source population $s$ (the American samples and the Japanese samples, in our case). The most probable source of a target invasive population sample $i$ is considered to be the population with the lowest corrected FST values with $i$ and the maximum assignment likelihood of $i$. We expect a lower corrected FST value between the USA and Portugal/ Madeira Island than between Asia and Portugal/ Madeira Island under the scenario of independent events of introduction and the opposite under the scenario of successive events of introduction.

We also plotted a neighbour joining (NJ) tree (Saitou and Nei 1987), based on Cavalli-Sforza and Edwards genetic distances (Cavalli-Sforza and Edwards 1967) with POPULATION software version 1.2.30 
(http://bioinformatics.org/ tryphon/populations/). The robustness of the tree topology was evaluated by carrying out 2,000 bootstrap replicates over loci. A tree based on Cavalli-Sforza and Edwards genetic distances (CavalliSforza and Edwards 1967) corrected for null alleles (Chapuis and Estoup 2007) was also built. The most probable source of a target invasive population sample $i$ is considered to be the population from outside Europe whose sample is clustering closest to $i$ in the tree.

Finally, we carried out Bayesian clustering analysis with STRUCTURE software (Pritchard et al. 2000) using all the samples from North America, Asia and Europe to determine the origin of the sampled Portuguese populations. The number of clusters tested, $K$, varied from 1 to 10 . As before, an admixture model with correlated allele frequencies (Falush et al. 2003), 20 runs per $K, 10^{6}$ iterations for the MCMC and $2 \times 10^{5}$ iterations for the burn-in period were used. CLUMPP (Jakobsson and Rosenberg 2007) and DISTRUCT (Rosenberg 2004) was used to identify the most frequent clustering patterns for each value of $K$ and to display the corresponding bar plots, respectively. This method identifies the most probable source of a target invasive population sample $i$ as the population for which the sample(s) is (are) the last to cluster with $i$ with increasing values of $K$. Thus, under the scenario of independent events of introduction, we expect that an American sample is the last one to still cluster with Portugal/Madeira Island with increasing values of $\mathrm{K}$. Conversely, under the scenario of successive events of introduction, we expect an Asian sample to be the last one to still cluster with Portugal/ Madeira Island with increasing values of $\mathrm{K}$.

\section{Results}

Standard genetic analyses

Three markers were monomorphic (M3, M30 and M49), even in the native area (but see Mallez et al. 2013, who found polymorphism at these markers in the native area, in analyses of collection and field samples). Genetic diversity was low to moderate in the USA and low to extremely low in invaded areas (see Table 1). In the native area, we detected up to eight alleles per locus and per sample (and up to 13 alleles per locus over all samples), with a mean number of alleles per sample (Mean Na) of 1.313 .38 and a mean expected heterozygosity (He) of $0.07 \quad 0.36$. Numerous monomorphic markers were detected in the invaded areas: 10 markers in Japan and 15 markers in Portugal/ Madeira, of the 16 considered. No more than two alleles per locus and per sample (and no more than three per locus over all samples in Japan) were detected, with a mean $\mathrm{Na}$ of 1.25 and a mean $\mathrm{He}$ of 0.06 at most. Ten samples in the native area and one sample in Portugal deviated significantly from HWE because of a heterozygous deficit (see Table 1). Significant linkage disequilibrium was found in 10 of the 624 pairwise tests carried out (after sequential Bonferroni correction, Sokal and Rohlf 1995), for four pairs of loci: M62 and Bx08; M51 and M56; M35 and M56 and M35 and M51. Examination of the results of FREENA analysis (Chapuis and Estoup 2007) showed that most of the deviation from HWE (especially in Portugal) and most of the significant linkage tests were accounted for by the presence of null alleles at the loci involved (estimates of null allele frequencies from 7 to $24 \%$, data not shown). However, null alleles were not systematically observed for a given marker across all the samples or for a given sample across all the markers. In addition, none of the samples or markers had more than $10 \%$ null alleles on average. We therefore used the entire dataset for further analyses.

Genetic structure analyses within geographic areas

In the USA, all samples displayed significant differentiation after correction for multiple testing (Fisher's exact tests, $p<10^{-5}$ ). Pairwise corrected estimates of FST values were also very high: from 0.06 to 0.76 (for more details see Table S1). The number of clusters could not be clearly inferred from the Bayesian clustering analysis, because $\Delta \mathrm{K}$ (Evanno et al. 2005) had several peaks, at different values of $K$ (see Figure S1). A biologically meaningful genetic structure occurred for large values of $K$ (see the examples of bar plots for several values of $K$ in Fig. 2A and all bar plots in Figure S2). Most samples were progressively unambiguously assigned to different clusters, at least until $K=14$. We also detected evidence of IBD (slope $=0.064, p=0.013$ ).

In Japan, the three samples from Iwate in the North were genetically identical, presenting one fixed allele for all the markers. All the remaining samples appeared to display significant differentiation (Fisher's exact tests, $p<10^{-5}$ ), with extremely high 


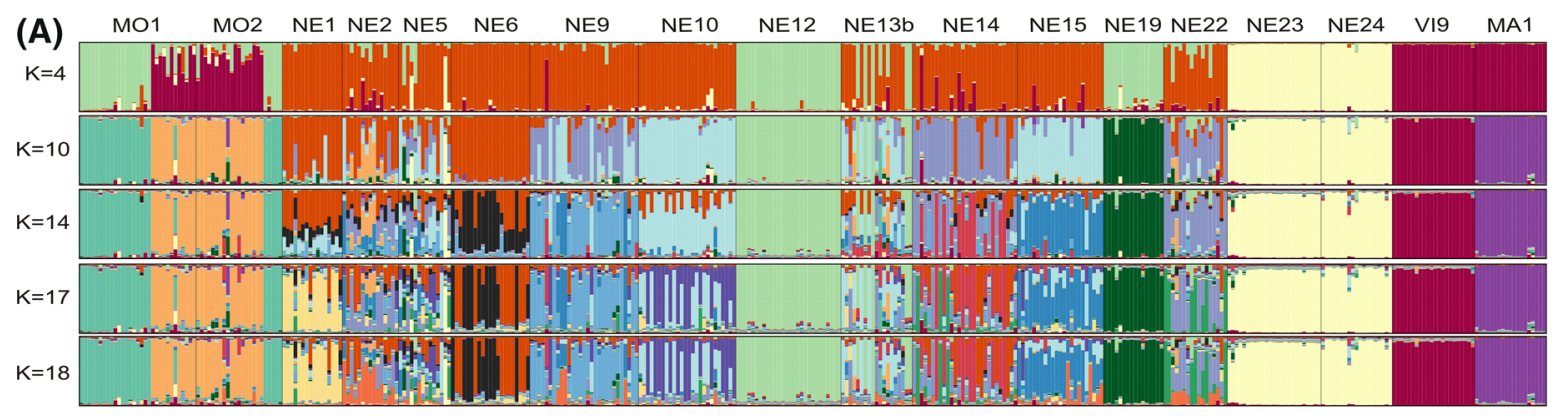

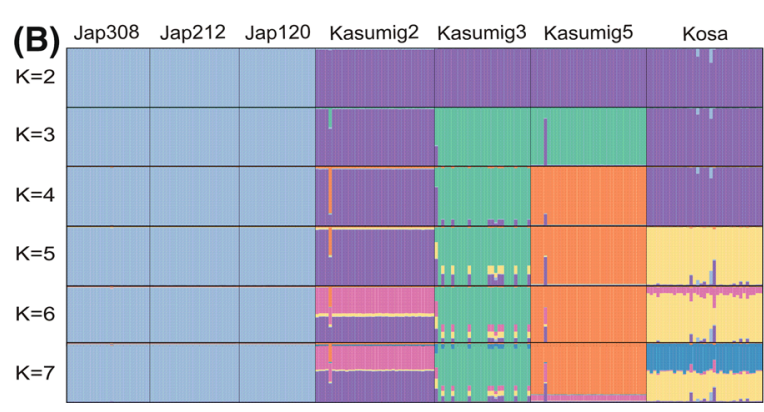

Fig. 2 Genetic structure of the PWN field samples within each area. Bar plots of the coefficients of co ancestry obtained in various STRUCTURE analyses with several values of $K$ for (A) a part of the native area, the USA and for the two invaded

corrected FST values, ranging from 0.63 to 0.99 (excluding the three identical samples, see Table $\mathrm{S} 1$ for more details). Strong genetic structure was also detected at the scale of the tree, with STRUCTURE. The $\Delta \mathrm{K}$ method (Evanno et al. 2005) inferred the existence of three clusters (see Figure S1), but likelihood values reached a plateau at $K=5$ and an examination of successive bar plots for co-ancestry suggested a meaningful structure for $K=5$ (see Fig. 2B).

In Portugal, eight of the nine samples were genetically identical and 162 individuals (of the 169 sampled) had identical homozygous multi-locus genotypes. The remaining sample (128S) differed significantly from seven of the other eight samples after correction for multiple testing (Fisher's exact tests, $p<0.017$ ). The result of one test was not significant $(\mathrm{Mad} 24 \mathrm{C}$ vs. $128 \mathrm{~S}$, Fisher's exact test, $p=0.065)$, probably because of the small size (seven individuals) of the Mad24C sample. The clustering analysis inferred a single cluster, grouping together the samples from mainland Portugal and Madeira (see Fig. 2C, Figure S1).

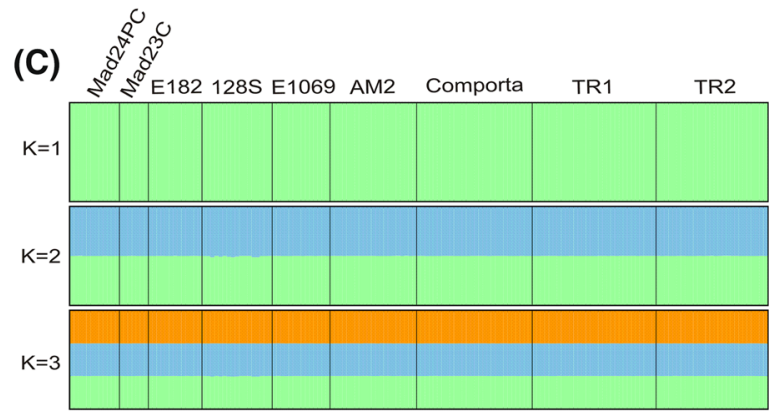

areas studied here, (B) Japan and (C) Portugal/Madeira. Each bar corresponds to one individual nematode and each cluster is represented with a particular colour

Relationships between populations from the different geographic areas

The results of the various analyses performed to clarify the relationships between the populations in different geographic areas are visualized and summarized in Fig. 3. The lowest FST values obtained with Portuguese samples always corresponded to American samples (see the example of one Portuguese sample in Fig. 3A and all Portuguese samples in Figure S3). The mean FST value (across samples) between Portugal/ Madeira and the USA was also lower than that between Portugal/Madeira and Japan, as shown by the dashed lines in Fig. 3A. Thus, the populations of Portugal/Madeira seem to be closer to the American populations than to the Japanese populations, on the basis of FST. Portuguese samples were assigned to American samples with the largest mean individual likelihood $\left(\mathrm{L}_{i \rightarrow s}\right.$, see the example of one Portuguese sample in Fig. 3B and all Portuguese samples in Figure S4). However, if we averaged across samples, Portugal was assigned to Japan with the largest mean individual likelihood (dashed lines on Fig. 3B). The 


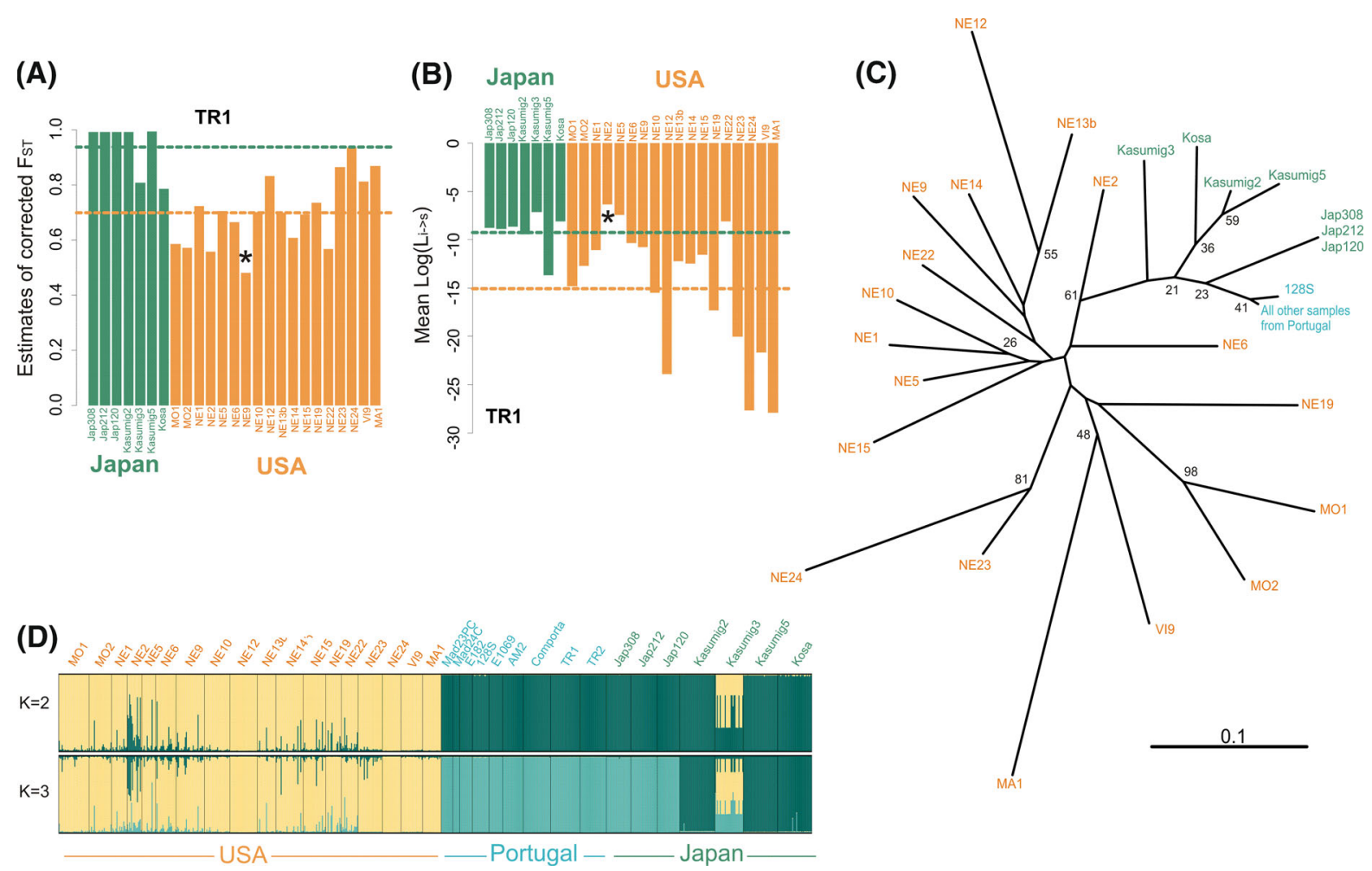

Fig. 3 Genetic relationships between populations from the different areas. The results of the four analyses performed are shown. (A) Weir and Cockerham estimates of FST corrected for null alleles (Chapuis and Estoup 2007; Weir and Cockerham 1984) between TR1, a Portuguese sample shown as an example, and each Japanese (in green) or American (in orange) sample. (B) Mean log likelihood of the multilocus individual assign ment $\left(\mathrm{L}_{i \rightarrow s}\right)$ of TR1 to each Japanese (in green) or American (in orange) sample. For these first two analyses, the sample displaying the lowest $F S T$ with TR1 or the largest mean $\mathrm{L}_{i \rightarrow s}$ is indicated with an asterisk. The mean values across samples

origin of the Portuguese samples is thus not clearly inferred with this statistic. On the NJ tree, the Portuguese samples were closer to the Japanese samples than to the American samples, for trees generated with both uncorrected and corrected Cavalli-Sforza and Edwards distances (Cavalli-Sforza and Edwards 1967; Chapuis and Estoup 2007; Fig. 3C, Figure S5, respectively). This result was robust to the use of other genetic distances (data not shown). Finally, Bayesian clustering analysis (Fig. 3D) showed that the Portuguese samples clustered with the Japanese samples at the lowest level of structuration $(K=2)$, with the Portuguese samples and three Japanese samples subsequently clustering together, for each area and for each parameter are represented by dashed lines. The results of $F S T$ and $\mathrm{L}_{i \rightarrow s}$ for other Portuguese samples are given in Figure S1 and Figure S2, respectively. (C) NJ tree based on Cavalli Sforza and Edwards distances (Cavalli Sforza and Edwards 1967). Bootstrap (on locus) values calculated over 2,000 replications are given as percentages (only values $>20 \%$ are shown). American samples are shown in orange, Japanese samples in green and Portuguese samples in blue. (D) Bar plots of the coefficients of co ancestry obtained with STRUCTURE for the first values of $K$. Each bar corresponds to one individual nematode and each cluster is represented by a particular colour

separately from the other Japanese samples, at $K=3$. This result was confirmed by a clustering analysis of the samples from invaded areas only (Portugal/ Madeira and Japan, data not shown).

\section{Discussion}

In this study, we investigated the genetic diversity and structure of natural PWN populations from around the world and the relationships between populations from native and invaded areas. Three main results were obtained: (1) we confirmed here, with a much larger number of samples, the existence of the strong genetic 
structure of PWN populations suggested by Mallez et al. (2013), consistent with notion that genetic drift has had a major effect on the genetic structure of PWN, (2) we found very low levels of polymorphism in the invaded areas, suggesting single introduction events, introduced populations with small effective sizes and clarifying the relationships between invasive populations within Europe and (3) we observed that classical and Bayesian population genetics methods were inconclusive concerning the invasion routes followed by PWN, and that more powerful inference methods are therefore required.

\section{Strong genetic structure in PWN populations}

We observed a strong spatial genetic structure of native $\mathrm{PWN}$ populations. A very low genetic diversity within samples from the native area compared to that between populations, highly significant differentiation tests, Bayesian clustering analysis and the extremely high values of pairwise FST were indicative of this structure. The very low within sample variability may have artificially increased $F S T$ values.

Such a genetic structure has already been reported in the native ranges of invasive species (e.g. for a Cuban lizard, by Kolbe et al. 2004). Our findings confirm those reported by Mallez et al. (2013), for a larger number of samples with hierarchical sampling in Nebraska. They confirm that the migration-drift equilibrium is highly biased towards significant genetic drift without compensation by efficient dispersal, even over short distances. The limited dispersal of the PWN may reflect the complexity of its dispersal process, which is principally dependent on an insect vector, Monochamus species (Akbulut and Stamps 2012; Linit 1988; Mamiya and Enda 1972; Sousa et al. 2001). This insect probably has a weak dispersal capacity, resulting in dispersal over short distances (Shibata 1986; Togashi 1990), particularly when the vector is heavily loaded with nematodes, potentially affecting its ability to fly (Akbulut and Linit 1999). The evidence of genetic IBD is also consistent with the probably spatially limited dispersal capacity of the PWN.

PWN must also overcome several potential obstacles to its dispersal. It must aggregate around pupal chambers, entering the beetles just before emergence, facilitating its entry into the tree via the maturation feeding sites of the beetles, for effective reproduction within the tree (reviewed in Futai 2013; Vicente et al. 2011). These steps may also contribute to the strong genetic drift observed in this system, because (1) the population of nematodes in an infested tree is aggregated into a small number of beetles that emerge from the tree (Akbulut and Linit 1999), (2) most beetles carry only a bit of nematodes (Kobayashi et al. 1984; Linit 1988) and (3) not all nematodes successfully invade pine trees (Togashi 1985), resulting in relatively low transmission rates (10 $20 \%$, Kobayashi et al. 1984; Togashi 1985).

Thus, the initial PWN population in a tree may be small, subsequently increasing exponentially in size. This creates considerable genetic drift, coupled with rates of dispersal between trees too low to homogenise genetic diversity.

Very low levels of polymorphism in invaded areas

Another finding in this study was the very low level or even complete absence of genetic diversity in the invaded areas, as observed in previous reports on the same species (Fonseca et al. 2012; Pereira et al. 2013; Vieira et al. 2007; Zhang et al. 2008; Zhou et al. 2007). However, this finding is remarkable in comparison with other invading species in which a loss of genetic diversity during invasion is not as common as previously expected (Bossdorf et al. 2005 for a review in plant invasive species; Roman and Darling 2007 for a review in aquatic invasions). The large number of monomorphic markers and the similarity between them across individuals (fixed alleles) are surprising at first glance for a sexual species (Futai 2013) and for microsatellite markers. However, these findings may be accounted for by the low level of intra-sample genetic diversity observed in the native area, together with the genetic bottlenecks and founder events often occurring during the introduction of species in new areas (Allendorf and Lundquist 2003; Sakai et al. 2001). Moreover, biological invasions tend to occur over short timescales, so mutational processes have very little effect on the genetic structure of invasive populations in the short term. Consequently, genetic structure is shaped mostly by demographic processes, such as intense demographic bottlenecks resulting in intense genetic bottlenecks, as in this study.

This very low level of genetic diversity provides information about the most probable number of introduction events. In cases of multiple introductions 
in a restricted area, such as mainland Portugal, Madeira or Japan, significant genetic diversity would be expected, due to admixture of the various introduced populations, particularly given the highly structured nature of native populations. The almost complete absence of polymorphism in mainland Portugal, Madeira and Japan therefore strongly suggests that a single introduction occurred in each of these areas, with each introduced population having small effective size. In the European context, these findings firmly suggest that the second outbreak detected in the centre of mainland Portugal in 2008 resulted from expansion of the first outbreak detected close to Lisbon in 1999. This conclusion contrasts with the findings of Valadas et al. (2012a), who suggested that multiple introductions had occurred. Our findings also suggest that the PWN populations on Madeira originated from mainland Portugal, given the near identity of the populations from Madeira and mainland Portugal and the first detection of PWN outbreak on Madeira 10 years after the first outbreak in mainland Portugal.

Intra-population genetic diversity is widely considered to be a prerequisite for adaptation to changing conditions and/or environment (Reed and Frankham 2003; Willi et al. 2006). Biological invasions have thus brought to light a genetic paradox (Allendorf and Lundquist 2003; Frankham 2005): the occurrence of successful invasions with low levels of genetic diversity. The case studied here provides a good example of this paradox, because PWN populations with low levels of diversity have managed to invade several regions around the world. There are several ecological mechanisms that might account for this paradox in the case of PWN: (1) the presence of appropriate insect vectors in each of the countries invaded (Akbulut and Stamps 2012; Mamiya and Enda 1972; Naves et al. 2007; Sousa et al. 2001), (2) the presence of susceptible hosts (Evans et al. 1996) and (3) the greater competitiveness of PWN than of its closely relative resident in the area, B. mucronatus (Cheng et al. 2009; Vincent et al. 2008). There is also some published evidence that a loss of genetic diversity (demonstrated with neutral markers) does not hamper the adaptive phenotypic variation of fitness-related traits (Dlugosch and Parker 2008) and that measurements of neutral genetic diversity are of only limited value for the prediction of quantitative genetic variability (Reed and Frankham 2001). Further studies are therefore required to determine whether invading PWN populations display significant adaptive genetic variability and whether this variability contributes to the success of PWN.

Worldwide invasion routes of PWN: the need for more powerful methods

The third main finding of this study was the difficulty elucidating the worldwide invasion routes of PWN. Depending on the analysis and the method used, we alternatively inferred two possible origins, North America and Asia, for the Portuguese outbreaks. The FST and mean FST values across samples suggested an American origin for all the Portuguese samples, whereas the $\mathrm{NJ}$ tree and the Bayesian clustering analysis suggested a Japanese origin for these samples. A discrepancy was also found in the mean individual assignment likelihood analysis, which gave inconsistent results, as the sample with the minimum mean individual assignment likelihood suggested an American origin and the mean individual assignment likelihood between samples suggested an Asian origin. This discrepancy partly results from large inter-sample variance of allelic frequency in North America. Previous studies have proposed an Asian origin for the European populations of PWN (Fonseca et al. 2012; Metge and Burgermeister 2008; Valadas et al. 2012b), essentially on the basis of tree analyses. Our finding with the NJ tree and Bayesian clustering is consistent with this conclusion. One key point here is that the conclusions drawn from these previous studies are no more robust than ours because (1) the methods used are included among those used here and (2) these previous studies did not use other methods possibly leading to alternative conclusions.

These inconclusive results highlight a major problem with traditional methods: a lack of statistical confidence evaluation for inferences of the source population of invasion. No statistical tests are carried out and no probabilities or type I or type II errors are calculated for classical and Bayesian clustering or distance methods. This makes it difficult to determine which result is the most likely when several alternatives are proposed (Estoup and Guillemaud 2010). However, these classical and Bayesian methods have proved both useful and conclusive in other cases of invasion (Ciosi et al. 2008; Facon et al. 2003; Kolbe et al. 2004; Papura et al. 2012; Perdereau et al. 2013; Wan et al. 2012). We can therefore put forward several 
hypotheses to account for the conflicting results obtained here: (1) the low level of diversity may have resulted in a lack of power to discriminate between the two possible alternatives, (2) the strong spatial genetic structure observed in the USA, requiring a very large sampling scheme to embrace most genetic variation of the native and (3) the lack of samples from some of the existing invaded areas, such as China or South Korea, potentially serving as sources for the invasion of Europe, as suggested by Figueiredo et al. (2013) on the basis of analyses of collection samples for PWN.

Given the limitations of classical and Bayesian methods, the use of recent model-based methods, such as the approximate Bayesian computation (ABC, Beaumont et al. 2002; Bertorelle et al. 2010; Guillemaud et al. 2010) may prove useful. The enthusiasm linked to the use of genetic data for reconstructing the history of invasive species was restricted by failures or technical limitations (Barun et al. 2013; Fitzpatrick et al. 2012). However, ABC make possible to perform extensive simulations of various/alternative hypothesis, which is needed to make reliable biological interpretations of invasion (Barun et al. 2013). Moreover, ABC offers several advantages (described by Estoup and Guillemaud 2010) that may be crucial in studies of PWN: (1) it takes complex scenarii into account, (2) it manages incomplete sampling by providing the possibility of considering unsampled "ghost" populations and, most importantly, (3) it makes it possible to evaluate quantitatively and to compare statistically the various competing scenarii, through the calculation of posterior probabilities. Finally, efforts should be made in future studies to obtain more representative samples. These new samples should provide a better representation of the genetic diversity existing around the world, more precisely describing the populations of the native area and all the main invaded areas.

Acknowledgments We would like to thank Arnaud Gaigher and Pedro Barbosa for technical support, Douglas LeDoux and Julia Thompson for American sampling and Eric Lombaert for fruitful discussions. This work was funded by the EU REPHRAME Project (KBBE.2010.1.4 09).

\section{References}

Abelleira A, Picoaga A, Mansilla JP, Aguin O (2011) Detection of Bursaphelenchus xylophilus, causal agent of pine wilt disease on Pinus pinaster in Northwestern Spain. Plant Dis 95:776
Akbulut S, Linit MJ (1999) Flight performance of Monochamus carolinensis (Coleoptera: Cerambycidae) with respect to nematode phoresis and beetle characteristics. Environ Entomol 28:1014 1020

Akbulut S, Stamps WT (2012) Insect vectors of the pinewood nematode: a review of the biology and ecology of Mon ochamus species. For Pathol 42:89 99

Allendorf FW, Lundquist LL (2003) Introduction: population biology, evolution, and control of invasive species. Conserv Biol 17:24 30. doi:10.1046/j.1523 1739.2003.02365.x

Barun A, Niemiller ML, Fitzpatrick BM, Fordyce JA, Sim berloff D (2013) Can genetic data confirm or refute his torical records? The island invasion of the small Indian mongoose (Herpestes auropunctatus). Biol Invasions 15:2243 2251. doi:10.1007/s105300130447 6

Beaumont MA, Zhang WY, Balding DJ (2002) Approximate Bayesian computation in population genetics. Genetics 162:2025 2035

Belkhir K, Borsa P, Chikhi L, Raufaste N, Bonhomme F (1996 2004) GENETIX 4.05, logiciel sous Windows TM pour la génétique des populations. Montpellier (France), Laboratoire Génome, Populations, Interactions, CNRS UMR 5000, Université de Montpellier

Benjamini Y, Hochberg Y (1995) Controlling the false discov ery rate a practical and powerful approach to multiple testing. J R Stat Soc Ser B Methodol 57:289 300

Bertorelle G, Benazzo A, Mona S (2010) ABC as a flexible framework to estimate demography over space and time: some cons, many pros. Mol Ecol 19:2609 2625

Bossdorf O, Auge H, Lafuma L, Rogers W, Siemann E, Prati D (2005) Phenotypic and genetic differentiation between native and introduced plant populations. Oecologia 144:1 11. doi:10.1007/s00442005 $0070 \mathrm{z}$

Boucher AC, Mimee B, Montarry J, Bardou Valette S, Belair G, Moffett P, Grenier E (2013) Genetic diversity of the golden potato cyst nematode Globodera rostochiensis and determi nation of the origin of populations in Quebec. Can Mol Phylogenet Evol 69:75 82. doi:10.1016/j.ympev.2013.05. 020

Castagnone C, Abad P, Castagnone Sereno P (2005) Satellite DNA based species specific identification of single indi viduals of the pinewood nematode Bursaphelenchus xylo philus (Nematoda: Aphelenchoididae). Eur J Plant Pathol 112:191 193. doi:10.1007/s10658 00405802

Cavalli Sforza LL, Edwards AWF (1967) Phylogenetic ana lysis. Models and estimation procedures. Am J Hum Genet 19:233 257

Chapuis M P, Estoup A (2007) Microsatellite null alleles and estimation of population differentiation. Mol Biol Evol 24:621 631. doi:10.1093/molbev/msl191

Cheng XY, Cheng FX, Xu RM, Xie BY (2008) Genetic variation in the invasive process of Bursaphelenchus xylophilus (Aphe lenchida: Aphelenchoididae) and its possible spread routes in China. Heredity 100:356 365. doi:10.1038/sj.hdy.6801082

Cheng XY, Xie PZ, Cheng FX, Xu RM, Xie BY (2009) Com petitive displacement of the native species Bursaphelen chus mucronatus by an alien species Bursaphelenchus xylophilus (Nematoda: Aphelenchida: Aphelenchoididae): a case of successful invasion. Biol Invasions 11:205 213

Ciosi M, Miller NJ, Kim KS, Giordano R, Estoup A, Guillemaud $\mathrm{T}$ (2008) Invasion of Europe by the western corn rootworm, 
Diabrotica virgifera virgifera: multiple transatlantic introductions with various reductions of genetic diversity. Mol Ecol 17:3614 3627

Dlugosch KM, Parker IM (2008) Invading populations of an ornamental shrub show rapid life history evolution despite genetic bottlenecks. Ecol Lett 11:701 709. doi:10.1111/j. 1461 0248.2008.01181.x

Dropkin VH, Foudin A, Kondo E, Linit MJ, Smith M, Robbins K (1981) Pinewood nematode: a threat to US forests? Plant Dis 65:1022 1027

Earl D, vonHoldt B (2012) STRUCTURE HARVESTER: a website and program for visualizing STRUCTURE output and implementing the Evanno method. Conserv Genet Resour 4:359 361. doi:10.1007/s126860119548 7

Estoup A, Guillemaud T (2010) Reconstructing routes of inva sion using genetic data: why, how and so what? Mol Ecol 19:4113 4130. doi:10.1111/j.1365 294X.2010.04773.x

Evanno G, Regnaut S, Goudet J (2005) Detecting the number of clusters of individuals using the software structure: a simulation study. Mol Ecol 14:2611 2620

Evans HF, McNamara DG, Braasch H, Chadoeuf J, Magnusson C (1996) Pest risk analysis (PRA) for the territories of European Union (as PRA area) on Bursaphelenchus xylo philus and its vectors in the genus Monochamus OEPP/ EPPO. Bulletin 26:199 249

Facon B, Pointier JP, Glaubrecht M, Poux C, Jarne P, David P (2003) A molecular phylogeography approach to biologi cal invasions of the New World by parthenogenetic Thiarid snails. Mol Ecol 12:3027 3039. doi:10.1046/j.1365 294X. 2003.01972.x

Facon B, Genton BJ, Shykoff J, Jarne P, Estoup A, David P (2006) A general eco evolutionary framework for under standing bioinvasions. Trends Ecol Evol 21:130 135. doi:10.1016/j.tree.2005.10.012

Falush D, Stephens M, Pritchard JK (2003) Inference of popu lation structure using multilocus genotype data: linked loci and correlated allele frequencies. Genetics 164:1567 1587

Figueiredo J et al (2013) Assessment of the geographic origins of pinewood nematode isolates via single nucleotide polymorphism in effector genes. PLoS One 8:e83542. doi:10.1371/journal.pone.0083542

Fitzpatrick BM, Fordyce JA, Niemiller ML, Reynolds RG (2012) What can DNA tell us about biological invasions? Biol Invasions 14:245 253. doi:10.1007/s10530 011 00641

Fonseca L et al (2012) The pinewood nematode, Bursaphelen chus xylophilus, in Madeira Island. Helminthologia 49:96 103

Fontaine MC, Gladieux P, Hood ME, Giraud T (2013) History of the invasion of the anther smut pathogen on Silene lat ifolia in North America. New Phytol 198:946 956. doi:10. 1111/nph.12177

Frankham R (2005) Invasion biology resolving the genetic paradox in invasive species. Heredity $94: 385$. doi:10.1038/ sj.hdy.6800634

Futai K (2013) Pinewood nematode, Bursaphelenchus xylo philus. Annu Rev Phytopathol 51:61 83

Goudet J (2002) Fstat, a program to estimate and test gene diversities and fixation indices. http://www2.unil.ch/ popgen/softwares/fstat.htm
Guillemaud T, Beaumont MA, Ciosi M, Cornuet JM, Estoup A (2010) Inferring introduction routes of invasive species using approximate Bayesian computation on microsatellite data. Heredity 104:88 99. doi:10.1038/hdy.2009.92

Jakobsson M, Rosenberg NA (2007) CLUMPP: a cluster matching and permutation program for dealing with label switching and multimodality in analysis of population structure. Bioinformatics 23:1801 1806

Kelager A, Pedersen J, Bruun H (2013) Multiple introductions and no loss of genetic diversity: invasion history of Japa nese Rose, Rosa rugosa, in Europe. Biol Invasions 15:1125 1141. doi:10.1007/s1053001203560

Keller SR, Taylor DR (2008) History, chance and adaptation during biological invasion: separating stochastic pheno typic evolution from response to selection. Ecol Lett 11:852 866

Kiritani K, Morimoto N (2004) Invasive insect and nematode pests from North America. Glob Environ Res 8:75 88

Kobayashi F, Yamane A, Ikeda T (1984) The japanese pine sawyer beetle as the vector of pine wilt disease. Annu Rev Entomol 29:115 135

Kolbe JJ, Glor RE, Schettino LRG, Lara AC, Larson A, Losos JB (2004) Genetic variation increases during biological invasion by a Cuban lizard. Nature 431:177 181. doi:10. 1038/nature02807

Linit MJ (1988) Nematode vector relationships in the pine wilt disease system. J Nematol 20:227 235

Mack RN, Simberloff D, Mark Lonsdale W, Evans H, Clout M, Bazzaz FA (2000) Biotic invasions: causes, epidemiology, global consequences, and control. Ecol Appl 10:689 710

Mallez S, Castagnone C, Espada M, Vieira P, Eisenback JD, Mota M, Guillemaud T, Castagnone Sereno P (2013) First insights into the genetic diversity of the pinewood nema tode in its native area using new polymorphic microsatel lite loci. PLoS One 8:e59165. doi:10.1371/journal.pone. 0059165

Mamiya Y (1972) Pine wood nematode Bursaphelenchus lig nicolus Mamiya and Kiyohara, as a causal agent of pine wilting disease. Rev Plant Protect Res 5:46 60

Mamiya Y (1975) The life history of the pine wood nematode, Bursaphelenchus lignicolus. Jpn J Nematol 5:16 25

Mamiya Y (1976) Pine wilt disease caused by the pine wood nematode, Bursaphelenchus lignicolus, in Japan. Jpn Agric Res Q 10:206 211

Mamiya Y (1983) Pathology of the pine wilt disease caused by Bursaphelenchus xylophilus. Annu Rev Phytopathol 21:201 220. doi:10.1146/annurev.py.21.090183.001221

Mamiya Y (1988) History of pine wilt disease in Japan. J Ne matol 20:219 226

Mamiya Y (2004) Pine wilt disease in Japan. In: Mota M, Vieira $\mathrm{P}$ (eds) The pinewood nematode, Bursaphelenchus xylo philus. Brill Academic, Leiden, pp 920

Mamiya Y, Enda N (1972) Transmission of Bursaphelenchus lignicolus (Nematoda: Aphelenchoididae) by Monoch amus alternatus (Coleoptera: Cerambycidae). Nemato logica 18:159 162

Metge K, Burgermeister W (2008) Analysis of Bursaphelenchus xylophilus (Nematoda: Parasitaphelenchidae) provenances using ISSR and RAPD fingerprints. In: Mota M, Vieira P (eds) Pine wilt disease: a worldwide threat to forest 
ecosystems. Springer, New York, pp 175 186. doi:10. $1007 / 978140208455315$

Moon YS, Cheon HM, Lee S (2007) Occurence of pine wilt disease, caused by Bursaphelenchus xylophilus, from Pinus koraiensis in Korea. J Nematol 39:87 88

Mota M, Braasch H, Bravo MA, Penas AC, Burgermeister W, Metge K, Sousa E (1999) First report of Bursaphelenchus xylophilus in Portugal and in Europe. Nematology 1:727 734

Naves PM, Camacho S, de Sousa EM, Quartau JA (2007) Transmission of the pine wood nematode Bursaphelenchus xylophilus through feeding activity of Monochamus gal loprovincialis (Col., Cerambycidae). J Appl Entomol 131:21 25. doi:10.1111/j.1439 0418.2006.01111.x

OEPP/EPPO (1997) Fiche informative sur les organismes de quarantaine: Bursaphelenchus xylophilus no $158 \mathrm{OEPP} /$ EPPO Bulletin 112

Paetkau D, Slade R, Burden M, Estoup A (2004) Genetic assignment methods for the direct, real time estimation of migration rate: a simulation based exploration of accuracy and power. Mol Ecol 13:55 65. doi:10.1046/j.1365 294X. 2004.02008.x

Papura D, Burban C, van Helden M, Giresse X, Nusillard B, Guillemaud T, Kerdelhué C (2012) Microsatellite and mitochondrial data provide evidence for a single major introduction for the Neartic leafhopper Scaphoideus titanus in Europe. PLoS One 7:e36882. doi:10.1371/journal.pone. 0036882

Pascual M et al (2007) Introduction history of Drosophila su bobscura in the New World: a microsatellite based survey using ABC methods. Mol Ecol 16:3069 3083

Perdereau E, Bagnères AG, Bankhead Dronnet S, Dupont S, Zimmermann M, Vargo EL, Dedeine F (2013) Global genetic analysis reveals the putative native source of the invasive termite, Reticulitermes flavipes, in France. Mol Ecol 22:1105 1119. doi:10.1111/mec.12140

Pereira F, Moreira C, Fonseca L, van Asch B, Mota M, Abrantes I, Amorim A (2013) New insights into the phylogeny and worldwide dispersion of two closely related nematode species, Bursaphelenchus xylophilus and Bursaphelenchus mucronatus. PLoS One 8. doi:10.1371/journal.pone. 0056288

Piry S, Alapetite A, Cornuet J M, Paetkau D, Baudouin L, Es toup A (2004) GENECLASS2: a software for genetic assignment and first generation migrant detection. J Hered 95:536 539. doi:10.1093/jhered/esh074

Pritchard JK, Stephens M, Donnelly P (2000) Inference of population structure using multilocus genotype data. Genetics 155:945 959

Puth LM, Post DM (2005) Studying invasion: have we missed the boat? Ecol Lett 8:715 721. doi:10.1111/j.1461 0248 . 2005.00774.x

Rannala B, Mountain JL (1997) Detecting immigration by using multilocus genotypes. Proc Natl Acad Sci 94:91979201

Raymond M, Rousset F (1995) An exact test for population differentiation. Evolution 49:1280 1283. doi:10.2307/ 2410454

Reed DH, Frankham R (2001) How closely correlated are molecular and quantitative measures of genetic variation? A meta analysis. Evolution 55:1095 1103. doi:10.1111/j. 0014 3820.2001.tb00629.x
Reed DH, Frankham R (2003) Correlation between fitness and genetic diversity. Conserv Biol 17:230 237. doi:10.1046/j. 1523 1739.2003.01236.x

Robertson L, Cobacho Arcos S, Escuer M, Santiago Merino R, Esparrago G, Abelleira A, Navas A (2011) Incidence of the pinewood nematode Bursaphelenchus xylophilus Steiner \& Buhrer, 1934 (Nickle, 1970) in Spain. Nematology 13:755 757

Roman J, Darling JA (2007) Paradox lost: genetic diversity and the success of aquatic invasions. Trends Ecol Evol 22:454 464. doi:10.1016/j.tree.2007.07.002

Rosenberg NA (2004) DISTRUCT: a program for the graphical display of population structure. Mol Ecol Notes 4:137 138. doi:10.1046/j.1471 8286.2003.00566.x

Rousset F (1997) Genetic differentiation and estimation of gene flow from $\mathrm{F}$ statistics under isolation by distance. Genetics 145:1219 1228

Rousset F (2008) GENEPOP' 007: a complete re implementa tion of the GENEPOP software for Windows and Linux. Mol Ecol Resour 8:103 106. doi:10.1111/j.1471 8286. 2007.01931.x

Saitou N, Nei M (1987) The neighbor joining method: a new method for reconstructing phylogenetic trees. Mol Biol Evol 4:406 425

Sakai AK et al (2001) The population biology of invasive spe cies. Annu Rev Ecol Syst 32:305 332. doi:10.1146/ annurev.ecolsys.32.081501.114037

Shibata E (1986) Dispersal movement of the adult Japanese pine sawyer, Monochamus alternatus hope (Coleoptera, Ce rambycidae) in a young pine forest. Appl Entomol Zool 21:184 186

Simberloff D et al (2013) Impacts of biological invasions: what's what and the way forward. Trends Ecol Evol 28:58 66

Sokal RR, Rohlf FJ (1995) Biometry The principles and practice of statistics in biological research, 3rd edn. W.H. Freeman and Company, New York, pp 236242

Soliman T, Mourits MCM, van der Werf W, Hengeveld GM, Robinet C, Lansink A (2012) Framework for modelling economic impacts of invasive species, applied to pine wood nematode in Europe. PLoS One 7. doi:10.1371/ journal.pone.0045505

Sousa E, Bravo MA, Pires J, Naves P, Penas AC, Bonifacio L, Mota MM (2001) Bursaphelenchus xylophilus (Nematoda; Aphelenchoididae) associated with Monochamus gallo provincialis (Coleoptera; Cerambycidae) in Portugal. Nematology 3:89 91. doi:10.1163/156854101300106937

Steiner G, Buhrer EM (1934) Aphelenchoides xylophilus, N. SP. A nematode associated with blue stain and other fungi in timber. J Agric Res 48:949 951

Strong DR, Pemberton RW (2000) Biological control of invading species risk and reform. Science 288:1969 1970. doi:10.1126/science.288.5473.1969

Suzuki K (2002) Pine wilt disease a threat to pine forest in Europe. Dendrobiology 48:71 74

Tares S, Abad P, Bruguier N, de Guiran G (1992) Identification and evidence for relationships among geographical isolates of Bursaphelenchus spp. (pinewood nematode) using homologous DNA probes. Heredity 68:157 164

Togashi K (1985) Transmission curves of Bursaphelenchus xylophilus (Nematoda: Aphelenchoididae) from its vector, 
Monochamus alternatus (Coleoptera: Cerambycidae), to pine trees with reference to population performnce. Appl Entomol Zool 20:246 251

Togashi K (1990) A field experiment on dispersal of newly emerged adults of Monochamus alternatus (Coleoptera: Cerambycidae). Res Popul Ecol 32:1 13

Tsutsui ND, Suarez AV, Holway DA, Case TJ (2000) Reduced genetic variation and the success of an invasive species. Proc Natl Acad Sci USA 97:5948 5953. doi:10.1073/pnas. 100110397

Valadas V, Barbosa P, Espada M, Oliveira S, Mota M (2012a) The pinewood nematode, Bursaphelenchus xylophilus, in Portugal: possible introductions and spread routes of a serious biological invasion revealed by molecular methods. Nematology 00:1 13

Valadas V, Laranjo M, Mota M, Oliveira S (2012a) Molecular characterization of Portuguese populations of the pine wood nematode Bursaphelenchus xylophilus using cyto chrome $b$ and cellulase genes. J Helminthol. doi:10.1017/ S0022149X12000673

van Wilgen BW, Moran VC, Hoffmann JH (2013) Some per spectives on the risks and benefits of biological control of invasive alien plants in the management of natural eco systems. Environ Manag 52:531 540. doi:10.1007/ s002670130099 4

Vicente C, Espada M, Vieira P, Mota M (2011) Pine wilt dis ease: a threat to European forestry. Eur J Plant Pathol. doi:10.1007/s10658 $0119924 \mathrm{x}$

Vieira P, Burgermeister W, Mota M, Metge K, Silva G (2007) Lack of genetic variation of Bursaphelenchus xylophilus in Portugal revealed by RAPD PCR analyses. J Nematol 39:118 126

Viglierchio DR, Schmitt RV (1983) On the methodology of nematode extraction from field samples: Baermann funnel modifications. J Nematol 15:438 444

Vincent B, Altemayer V, Roux Morabito G, Naves P, Sousa E, Lieutier F (2008) Competitive interaction between
Bursaphelenchus xylophilus and the closely related species Bursaphelenchus mucronatus. Nematology 10:219 230. doi:10.1163/156854108783476403

Wan XW, Liu YH, Zhang B (2012) Invasion history of the oriental fruit fly, Bactrocera dorsalis, in the Pacific Asia Region: two main invasion routes. PLoS One 7. doi:10. 1371/journal.pone.0036176

Weir BS, Cockerham CC (1984) Estimating F statistics for the analysis of population structure. Evolution 38:1358 1370

Willi Y, Van Buskirk J, Hoffmann AA (2006) Limits to the adaptive potential of small populations. Annu Rev Ecol Evol Syst 37:433 458. doi:10.1146/annurev.ecolsys.37. 091305.110145

Wilson JRU, Dormontt EE, Prentis PJ, Lowe AJ, Richardson DM (2009) Something in the way you move: dispersal pathways affect invasion success. Trends Ecol Evol 24:136 144. doi:10.1016/j.tree.2008.10.007

Wingfield MJ, Blanchette RA, Nicholls TH, Robbins K (1982) The pine wood nematode: a comparison of the situation in the United States and Japan. Can J For Res 12:71 75. doi:10.1139/x82 010

Yoder M et al (2006) DESS : a versatile solution for preserving morphology and extractable DNA of nematodes. Nema tology 8:367 376

Zepeda Paulo FA et al (2010) The invasion route for an insect pest species: the tobacco aphid in the New World. Mol Ecol 19:4738 4752. doi:10.1111/j.1365 294X.2010.04857.x

Zhang K et al (2008) Molecular phylogeny of geographical isolates of Bursaphelenchus xylophilus: implications on the origin and spread of this species in China and worldwide. J Nematol 40:127 137

Zhou ZH, Sakaue D, Wu BY, Hogetsu T (2007) Genetic structure of populations of the pinewood nematode Bur saphelenchus xylophilus, the pathogen of pine wilt disease, between and within pine forests. Phytopathology 97:304 310. doi:10.1094/phyto 9730304 